\title{
Impact of Maternal Severe Vitamin D Deficiency on Fetal Outcome
}

Dr. Rugea Mahmud Mahmmed ${ }^{1 *}$, Prof. Dr. Namah AL-Sadik EL-Houni ${ }^{2}$, Dr. Mohamed Masood Alferjani ${ }^{3}$

\footnotetext{
${ }^{1,2}$ Department of Peadiatric, AL- Mugref Hospital, Faculty of Medicine, Ejdabiya University-libya

${ }^{3}$ Assistant Prof., Department of Pediatric Faculty of Medicine Garyounis University -Libya
}

DOI: $10.36347 /$ sjams.2020.v08i09.006

| Received: 24.08.2020 | Accepted: 01.09.2020 | Published: 09.09.2020

*Corresponding author: Rugea Mahmud Mahmmed

\section{Abstract}

\section{Original Research Article}

Vitamin D is known to play an important role in bone metabolism and immune system regulation. Objective: to evaluate the impact of maternal vitamin D level on Baby hematological \& anthropometric measurements. Patients and methods: prospective cross sectional study was conducted on 22 women with their babies who delivered vaginally at AL- Jamhoria hospital labour room with gestational age $>37$ week. The verbal consent was taken with Full out the questions Form. Maternal venous blood for biochemical (vitamin D, PTH, s. Ca+, s. Po4, s. Alk. Ph) \& baby venous blood for biochemical (vit. D, s.Ca+, s. PO4, s. Alk. Ph) and anthropometric measurements (B. weight, Length, Head circumference) were taken immediately after birth by same person. Results and Conclusion: 22 women with their babies, aged between 19- 42 year with mean $(31.5 \pm 5.83)$ where $5(22.7 \%)$ Of them received vitamin D injection during pregnancy. Mean maternal vitamin D \& parathyroid hormone levels were (3.29 $\pm 1.36 \& 53.2 \pm 2.2)$ respectively, the mean maternal calcium, phosphate \& Alkaline phosphatase were $\{(8.5 \pm 0.42),(3.66 \pm 0.46),(77.5 \pm$ $2.2)\}$ respectively. The mean baby vitamin D level is $3.75 \pm 2.04$ where $10(45.5 \%)$ of babies had features of vitamin $\mathrm{D}$. The mean baby calcium, phosphate, Alkaline phosphatase were $\{(9.20 \pm 0.56),(5.20 \pm 0.7),(93.5 \pm 3.20)\}$ respectively. The mean baby birth weight, Length, Head circumference were $\{(3.35 \pm 0.45),(49.95 \pm 1.17),(34.79 \pm 1.08)\}$ respectively. The significant correlation were exists between Maternal vitamin D \& baby vitamin D \& between Maternal parathyroid hormone \& Baby Alkaline phosphatase.

Keywords: Maternal Severe Vitamin D.

Copyright @ 2020: This is an open-access article distributed under the terms of the Creative Commons Attribution license which permits unrestricted use, distribution, and reproduction in any medium for non-commercial use (NonCommercial, or CC-BY-NC) provided the original author and source are credited.

\section{INTRODUCTION}

Vitamin D is known to play an important role in bone metabolism through regulation of calcium and phosphate homeostasis and may also play an important role in immune system regulation it is produced by the body during exposure to sunlight, but is also found in oily fish, eggs and fortified food products. Infants are born with low vitamin D stores and are dependent on breast milk, sunlight or supplements as sources of vitamin $\mathrm{D}$ in the first few months of life. As the vitamin $\mathrm{D}$ content of breast milk is dependent on maternal vitamin $\mathrm{D}$ status and is often low, and sun exposure may be restricted for infants living at higher latitudes or for cultural or other reasons, infants are particularly vulnerable to vitamin D deficiency and its leading cause to bone malformation (rickets), seizures and difficulty breathing [1].

Human milk typically contains a vitamin D concentration of 25 IU per liter or less. Therefore, a supplement of 400 IU per day of vitamin $D$ is recommended for all breastfed infants [2].

- Vitamin D levels [3]

\begin{tabular}{|l|l|}
\hline Serum 25 $-(\mathbf{O H}) \mathbf{D}$ concentration level & Vitamin D status \\
\hline$<25 \mathrm{nmol} / \mathrm{l}(10 \mathrm{micrograms} / \mathrm{l})$ & Deficient \\
\hline $25-50 \mathrm{nmol} / \mathrm{l}(10-20 \mathrm{micrograms} / \mathrm{l}$ & Insufficient \\
\hline $50-75 \mathrm{nmol} / \mathrm{l}(20-30 \mathrm{micrograms} / \mathrm{l})$ & Adequate \\
\hline$>75 \mathrm{nmol} / \mathrm{l}(30 \mathrm{micrograms} / \mathrm{l})$ & Optimal \\
\hline
\end{tabular}




\section{Aims of the Study}

- To evaluate impact of Low Maternal vitamin D level on neonatal hematological (vit. D, s. Ca+, s. Po4, Alkaline phosphate)

- To evaluate impact of Low Maternal vitamin D level on neonatal anthropometric measurements (B. weight, Length, Head circumference)

\section{PATIENTS AND METHODS STUDY DESIGN}

Prospective cross- sectional study was conducted at January 2012. Study population: prospective cross sectional study was conducted on 22 women with their babies who delivered vaginally at AL- Jamhoria hospital labour room were included in our study, aged between 19- 42 years old with gestational age $>37$ week. The verbal consent was taken with the following information: mother's clothes, $\mathrm{H} / \mathrm{O}$ sun exposure, hour of exposure, House condition, mother's diet ( vitamin $\mathrm{D}$ rich diet), $\mathrm{H} / \mathrm{O}$ calcium tablet ingestion \& vitamin D injection, H/O chronic liver \& chronic kidney disease, H/O malabsorption disease, $\mathrm{H} / \mathrm{O}$ Gut resection, $\mathrm{H} / \mathrm{O}$ parathyroid disease, $\mathrm{H} / \mathrm{O}$ inherited vitamin $\mathrm{D}$ metabolism disease, $\mathrm{H} / \mathrm{O}$ maternal drugs like antituberculous, anticonvulsion, H/O chronic use of glucocorticoid drug.

Sitting: study done at AL- Jamhoria Hospital Labour room (it is a governmental and referral center covering a large number of pregnant women from rural and urban areas of eastern part of Libya).

Study period: 1 month for data collection and the rest for data analysis \& writing. Blood samples and measurements: - Maternal venous blood for biochemical (vitamin D, PTH, s. Ca+, s. Po4, s. Alk. PH) were taken \& baby venous blood for biochemical (vit. D, s.Ca+, s. PO4, s. Alk.Ph) and anthropometric measurements for baby (B. weight, Length, Head circumference) were taken immediately after birth $\&$ all were done by same person.

\section{DATA ANALYSIS}

Statistical analysis were performed using SPSS window version 16 statistical significance was tested by using Chi-Square test \& the correlation were analyzed by Pearson's correlation, the results were evaluated as significance with $\mathrm{P}$ - value $(\leq 0.05) \&(\mathrm{r})$. Beside standard descriptive statistical calculations (Mean \pm $\mathrm{SD})$.

\section{RESULTS}

\section{Maternal hematological indices}

22 Women were included in our study aged between 19- 42 year with mean $(31.5 \pm 5.83) \& 5$ (22.7 $\%)$ of mothers received vitamin $\mathrm{D}$ injection

Where:

1. Mean maternal vitamin D level is $3.29 \pm 1.36$ with p- value (0.000).

2. Mean maternal parathyroid hormone level is $53.2 \pm 2.2$ with p-value (1)

3. Mean maternal calcium level is $8.5 \pm 0.42$ with p- value (0.285).

4. Mean maternal phosphate level is $3.66 \pm 0.46$ with p- value (0.848).

5. Mean maternal alkaline phosphatase level is $77.5 \pm 2.2$ with $\mathrm{p}$-value (1).

Table-1: Maternal hematological indices

\begin{tabular}{|l|l|l|l|}
\hline Group & No & Mean \pm SD & P-value \\
\hline vit D & 22 & $3.29 \pm 1.36$ & 0.000 \\
\hline PTH & 22 & $53.2 \pm 2.2$ & 1 \\
\hline Ca $^{+}$ & 22 & $8.5 \pm 0.42$ & 0.285 \\
\hline PO4 & 22 & $3.66 \pm 0.46$ & 0.848 \\
\hline ALP & 22 & $77.5 \pm 2.2$ & 1 \\
\hline
\end{tabular}

\section{Baby Hematological indices}

22 Babies were included in our study where 10 $(45.5 \%)$ of them had features of vitamin D deficiency with

1. Mean baby vitamin D level is $3.75 \pm 2.04$ with p- value (0.000).

2. Mean Baby calcium level is $9.20 \pm 0.56$ with $\mathrm{p}$ value (0.782).

3. Mean Baby phosphate level is 5.20 0.77 with p- value (0.917).

4. Mean Baby alkaline phosphatase level is $93.5 \pm$ 3.20 with $\mathrm{p}$ - value (1).

Table-2: Baby Hematological indices

\begin{tabular}{|c|l|l|l|}
\hline Group & No & Mean \pm SD & P-value \\
\hline Vit D & 22 & $3.75 \pm 2.04$ & 0.000 \\
\hline Ca+ & 22 & $9.20 \pm 0.56$ & 0.782 \\
\hline Po4 & 22 & $5.20 \pm 0.77$ & 0.917 \\
\hline ALP & 22 & $93.5 \pm 3.20$ & 1 \\
\hline
\end{tabular}

Baby anthropometric measurements

22 Baby were included in our study with

1. Mean Baby Birth weight is $3.35 \pm 0.45$ with Pvalue (0.900).

2. Mean Baby Length is $49.95 \pm 1.17$ with $\mathrm{P}$ value (0.030).

3. Mean Baby Head Circumference is $34.79 \pm$ 1.08 with $\mathrm{P}$ - value $(0.035)$. 
Table-3: Baby anthropometric measurements

\begin{tabular}{|l|l|l|l|}
\hline Anthropometric measurement & No & Mean \pm SD & P-value \\
\hline Wt & 22 & $3.35 \pm 0.45$ & 0.900 \\
\hline Lt & 22 & $49.95 \pm 1.17$ & 0.030 \\
\hline Hc & 22 & $34.79 \pm 1.08$ & 0.035 \\
\hline
\end{tabular}

Relationship between Maternal Vitamin D \& Baby Hematological indices

1. There is highly significant correlation that exists between Maternal vitamin D level \&
Baby vitamin D level with $\mathrm{r}=0.781 \& \mathrm{p}$ value (0.000).

2. No correlation that exists between maternal vitamin D \& other baby hematological indices.

Table-4: Relationship between Maternal Vitamin D \& Baby Hematological indices

\begin{tabular}{|l|l|l|l|l|}
\hline Baby Hematological induces & Mean \pm SD M. vit D & Mean \pm SD & \multicolumn{2}{l|}{ Pearson Correlation } \\
\cline { 3 - 5 } & & & r & P \\
\hline B. vit D & $3.29 \pm 1.36$ & $3.75 \pm 2.04$ & 0.781 & 0.000 \\
\hline B. ca+ & $3.29 \pm 1.36$ & $9.20 \pm 0.56$ & -0.043 & 0.849 \\
\hline B. po4 & $3.29 \pm 1.36$ & $5.20 \pm 0.77$ & 0.115 & 0.612 \\
\hline B. ALP & $3.29 \pm 1.36$ & $93.5 \pm 3.20$ & -0.103 & 0.647 \\
\hline
\end{tabular}

Relationship between Maternal vitamin D \& Baby anthropometric measurements

1- There are no correlation exists between maternal vitamin D level \& Baby parameters

Table-5: Relationship between maternal vitamin D level \& Baby anthropometric measurements

\begin{tabular}{|l|l|l|l|l|}
\hline Baby anthropometric Measurements & Mean \pm SD M. vit D & \multirow{2}{*}{ Mean \pm SD } & \multicolumn{2}{|l|}{ Pearson Correlation } \\
\cline { 3 - 5 } & & & r & P \\
\hline B. wt & $3.29 \pm 1.36$ & $3.35 \pm 0.45$ & -0.05 & 0.820 \\
\hline B. Lt & $3.29 \pm 1.36$ & $49.95 \pm 1.17$ & -0.182 & 0.419 \\
\hline B. Hc & $3.29 \pm 1.36$ & $34.79 \pm 1.08$ & -0.061 & 0.788 \\
\hline
\end{tabular}

Relationship between Maternal parathyroid hormone \& Baby Hematological indices

There is significant correlation that exists only between Maternal serum parathyroid hormone level \&
Baby serum Alkaline phosphatase level with $\mathrm{r}=(0.455)$ \& P-value $(0.033)$

Table-6: Relationship between Maternal parathyroid hormone \& Baby Hematological indices

\begin{tabular}{|l|l|l|l|l|}
\hline Baby Hematological induces & Mean \pm SD M. PTH & Mean \pm SD & \multicolumn{2}{l|}{ Pearson Correlation } \\
\cline { 3 - 5 } & & & r & P \\
\hline B. vit D & $53.2 \pm 2.26$ & $3.75 \pm 2.04$ & -0.010 & 0.965 \\
\hline B. ca+ & $53.2 \pm 2.26$ & $9.20 \pm 0.56$ & 0.156 & 0.487 \\
\hline B. po4 & $53.2 \pm 2.26$ & $5.20 \pm 0.77$ & -0.054 & 0.810 \\
\hline B. ALP & $53.2 \pm 2.26$ & $93.5 \pm 3.20$ & 0.455 & 0.033 \\
\hline
\end{tabular}

Relationship between Maternal parathyroid hormone \& Baby anthropometric measurements

1 -there is no correlation that exists between maternal serum parathyroid hormone \& Baby parameters

Table-7: Relationship between Maternal parathyroid hormone \& Baby anthropometric measurements

\begin{tabular}{|l|l|l|l|l|}
\hline Baby anthropometric & $\begin{array}{l}\text { Mean } \pm \text { SD M. } \\
\text { Measurements }\end{array}$ & Mean \pm SD & \multicolumn{2}{|l|}{ Pearson Correlation } \\
\cline { 4 - 5 } & PTH & & r & P \\
\hline B. Lt & $53.2 \pm 2.26$ & $3.35 \pm 0.45$ & 0.207 & 0.355 \\
\hline B. Hc & $53.2 \pm 2.26$ & $49.95 \pm 1.17$ & -0.034 & 0.880 \\
\hline
\end{tabular}

\section{DiSCUSSION}

\section{Maternal \& baby hematological indices}

The potential impact of vitamin D deficiency during pregnancy on maternal and neonatal health has attracted much interest in recent years. It has been suggested that maintaining adequate maternal stores of vitamin D during pregnancy is of vital importance for both mothers and neonates to ensure skeletal and extraskeletal health [4].There are no data to support routine screening for vitamin $\mathrm{D}$ deficiency in pregnancy in terms of health benefits or cost effectiveness. There is an argument that some groups of women who are pregnant should have a screening test: for example, on 
the basis of skin colour or coverage, obesity, risk of preeclampsia or gastroenterological conditions limiting fat absorption. As the test is expensive, offering it to all atrisk women may not be cost effective compared to offering universal supplementation, particularly as treatment is regarded as being very safe. At present, there are no data to support a strategy of measurement followed by treatment in the general female population. Measurement of vitamin $\mathrm{D}$ in hypocalcaemic or symptomatic woman as part of their management continues to be applicable. This includes women with a low calcium concentration, bone pain, gastrointestinal disease, previous child with rickets and those receiving drugs which reduce vitamin D [5]. The blood calcium, hormones and skeleton are normal at birth in the offspring of mothers who are severely vitamin D deficient [6]. During pregnancy and lactation significant changes in calcium \& vitamin D metabolism occur to provide the needs required for fetal bone mineralization where in early pregnancy increases of calcium absorption reaching its peak in the last trimester. The transfer is counterbalanced by increased intestinal absorption and decreased urinary excretion of calcium [7].

\section{Relationship between Maternal vitamin D \& Baby hematological indices}

Highly significant correlation that were exists between Maternal vitamin D \& Baby vitamin D level \& this is result going with Monangi, N. et al. [8], Spyridon N Karras, et al. [4] \& Mohamed A, et al. [9], Grant et al. [10], Sablok, et al. [11].

\section{Relationship between Maternal vitamin D \& Baby anthropometric measurements}

No correlation were exists between them \& this is result going with Rodriguez, et al. [11], Miriam katzman. [3], Shand A, et al. [12] \& Gale, et al. [13]. Mallet, et al. [14] \& Javaid MK et al. [15].

\section{Relationship between Maternal parathyroid hormone \& Baby hematological indices}

Significant correlation was exists between maternal PTH \& baby alkaline phosphatase \& no correlation with other indices. Where no other study exists to compare with it.

\section{Relationship between Maternal parathyroid hormone \& Baby anthropometric measurements}

No correlation were exists between them \& no studies have addressed this correlation. Several studies "suggest that infants born to mothers with inadequate vitamin D status are highly dependent on a regular supply of vitamin D through diet, supplements or exposure to ultraviolet light." Because mom's vitamin D status during pregnancy directly affects baby's vitamin D stores at birth and particularly during the first 2-3 months, it would be very helpful for pregnant women to make sure they are getting enough vitamin $\mathrm{D}$. It is easy to determine if mom is vitamin $\mathrm{D}$ deficient by using a simple blood test to check parathyroid hormones. If these hormones are elevated, it can indicate a deficiency in vitamin D. Baby's fetal stores of vitamin $\mathrm{D}$ are sufficient for around 3 months if baby gets very little sunlight, but will last much longer if baby is exposed to sunlight regularly. Daily vitamin D supplementation with oral cholecalciferol or ergocalciferol is safe in pregnancy. The 2012 recommendation from UK Chief Medical Officers and NICE guidance state that all pregnant and breastfeeding women should be informed about the importance of vitamin $D$ and should take 10 micrograms of vitamin D supplements daily. Particular care should be taken over high-risk women [5].

\section{LIMITATIONS}

- 1 st limitation related to small sample size.

- 2nd limitation related to the vitamin D analysis wasn't available in all Labs.

- 3rd limitation no control group among our sample where all of them severe vitamin D deficient.

\section{RECOMMENDATIONS}

1. Vitamin D deficiency in pregnant women and their children is preventable major health problem so institute routine screen for all women.

2. Further research should focus on the potential benefits and optimal dosing of vitamin D use in pregnancy \& should be aimed to prevent problems in neonate $\&$ infant.

3. Setting up a newborn for healthy future begins at conception but we must collaborate to maintain health throughout infancy, childhood and beyond.

\section{REFERENCES}

1. World Health Organization WHO. Vitamin D supplementation in infant. E Library of Evidence for Nutrition Actions (eLENA). 2017; 16:48 CET.

2. Centers for Disease Control and Prevention (CDC). Vitamin D Supplementation, Division of Nutrition, Physical Activity, and Obesity, National Center for Chronic Disease Prevention and Health.

3. Guidelines for the treatment and prophylaxis of vitamin D deficiency and rickets in children adolescents. Barts and the London NHS Trust. Jan 2012.

4. Karras SN, Shah I, Petroczi A, Goulis DG, Bili H, Papadopoulou F, Harizopoulou V, Tarlatzis BC, Naughton DP. An observational study reveals that neonatal vitamin $\mathrm{D}$ is primarily determined by maternal contributions: implications of a new assay on the roles of vitamin D forms. Nutrition journal. 2013 Dec 1;12(1):77.

5. S Robinson, C Nelson-Piercy, NC Harvey, P Selby, JO Warner. Vitamin D in Pregnancy. Royal 
College of Obstetricians and Gynaecologists, Scientific Impact Paper. 43, 2017.

6. Aly H, Abdel-Hady H. Vitamin D and the neonate: An update. Journal of Clinical Neonatology. 2015 Jan 1;4(1):1.

7. Urrutia-Pereira M, Solé D. Vitamin D deficiency in pregnancy and its impact on the fetus, the newborn and in childhood. Revista Paulista de Pediatria (English Edition). 2015 Mar 1;33(1):104-13.

8. Monangi N, Slaughter JL, Dawodu A, Smith C, Akinbi HT. Vitamin D status of early preterm infants and the effects of vitamin D intake during hospital stay. Archives of Disease in ChildhoodFetal and Neonatal Edition. 2014 Mar 1;99(2):F166-8.

9. Aly YF, El Koumi MA, Abd El Rahman RN. Impact of maternal vitamin $D$ status during pregnancy on the prevalence of neonatal vitamin D deficiency. Pediatric reports. 2013 Feb 5;5(1).

10. Grant CC, Stewart AW, Scragg R, Milne T, Rowden J, Ekeroma A, Wall C, Mitchell EA, Crengle S, Trenholme A, Crane J. Vitamin D during pregnancy and infancy and infant serum 25hydroxyvitamin D concentration. Pediatrics. 2014 Jan 1;133(1):e143-53.

11. Rodriguez A, García- Esteban R, Basterretxea M, Lertxundi A, Rodríguez- Bernal C, Iniguez C, Rodriguez- Dehli C, Tardon A, Espada M, Sunyer
J, Morales E. Associations of maternal circulating 25- hydroxyvitamin D3 concentration with pregnancy and birth outcomes. BJOG: An International Journal of Obstetrics \& Gynaecology. 2015 Nov;122(12):1695-704.

12. Shand AW, Nassar N, Von Dadelszen P, Innis SM, Green TJ. Maternal vitamin D status in pregnancy and adverse pregnancy outcomes in a group at high risk for pre- eclampsia. BJOG: An International Journal of Obstetrics \& Gynaecology. 2010 Dec;117(13):1593-8.

13. Gale CR, Robinson SM, Harvey NC, Javaid MK, Jiang B, Martyn CN, Godfrey KM, Cooper C. Maternal vitamin D status during pregnancy and child outcomes. European journal of clinical nutrition. 2008 Jan;62(1):68-77.

14. Mallet E, Gügi B, Brunelle P, Henocq A, Basuyau JP, Lemeur H. Vitamin D supplementation in pregnancy: a controlled trial of two methods. Obstetrics and gynecology. 1986 Sep;68(3):300-4.

15. Javaid MK, Crozier SR, Harvey NC, Gale CR, Dennison EM, Boucher BJ, Arden NK, Godfrey KM, Cooper C, Princess Anne Hospital Study Group. Maternal vitamin D status during pregnancy and childhood bone mass at age 9 years: a longitudinal study. The Lancet. 2006 Jan 7;367(9504):36-43. 